\title{
An Experimental Study of the Behavioral Effects of Carbethoxysyringoyl Methylreserpate (Singoserp ${ }^{\text {B) }}$
}

\author{
James G. Miller and Leonard Uhr \\ Mental Health Research Institute, Department of Psychiatry, \\ University of Michigan, Ann Arbor, Michigan
}

Received April 20, 1959

Physiological studies and preliminary behavioral screening with animals have indicated that syrosingopine ${ }^{1}$ (carbethoxysyringoyl methylreserpate), a reserpine derivative, is a hypotensive drug with little or no "tranquilizing" action. The present study was designed to explore and check on these findings, as related to adverse behavioral effects, in a controlled experiment with human patients. The Driver Trainer and Ortho-Rater, used in previous experiments (Marquis et al., 1957; Kelly et al., 1958b) to test for possible adverse behavioral effects of psychoactive drugs were employed to test the effects of syrosingopine on psychomotor and visual functions. Simple tests of attention, alertness, tempo, and mood were used to explore some of the other common modes of action of a psychoactive drug.

\section{METHOD}

A counterbalanced double-blind design, in which all patients acted as their own controls, was employed as follows: Each patient was given three drug treatments: (a) $1 \mathrm{mg}$ syrosingopine; (b) $5 \mathrm{mg}$ syrosingopine; and (c) a placebo. Each treatment was taken daily for a period of 28 days. All tablets were identical in taste and appearance. Tablets were packaged in envelopes and dispensed daily, between 7:00 and 8:00 A.M., to each patient, who took the tablet in the presence of one of the testers. Neither tester nor patient was aware of the identity of any of the tablets. All six possible orderings of the three drugs were followed for an equal number of patients, so that ordering effects would be counterbalanced and canceled out across the entire group. The patients were prisoners at the State Prison of Southern Michigan and all served as paid volunteers.

1 Singoserp ${ }^{\circledR}$, Ciba Pharmaceutical Products, Inc., Summit, New Jersey. 
The prison routine allowed us to exercise unusually close supervision over the day-to-day details of the experiment. All patients reported at the same time each morning for their daily tablets. Behavioral testing was done at the same time of day for each patient at the termination of each treatment. All patients were also given a pre-experiment training and practice session.

Thirty-two men completed the experiment. One man asked to be dropped immediately before the first testing session, apparently because of fear that he would not perform well on the tests, and was replaced by another patient. Two men were dropped because they did not report at the time assigned for testing and it was not possible to reschedule them. Two men were not used in the data analysis because of their difficulty in reading and observing test materials: one because of broken glasses, the other because of illiteracy. All other patients completed the entire course of treatment with no ill effects.

Thirty-five objectively measured variables were scored from the various aspects of the patient's performance on ten different tests. These tests, together with scores obtained on each, are described below.

A. Driver Test ( 7 scores). The American Automobile Association's "Auto Trainer" was used to test complex psychomotor skills of the sort used while driving an automobile. The patient operates the trainer by working the controls of a conventional shift automobile. A treadmill-like belt about 10 feet long, painted to resemble a winding road, extends in front of the control unit. A model car, connected to the steering wheel and operated by the patient, rests on the belt. The patient's job is to keep the car on the road and to brake the car whenever a red light appears. For a more complete description of this apparatus, see Marquis et al. (1957).

Patients were given trials as follows: twenty revolutions of the belt at a fixed low speed, twenty at a fixed high speed, and twenty at a speed controlled by the patient. Six reaction-time determinations were interspersed irregularly through the first two trials.

Accuracy, or proficiency, of driving in this situation is measured in terms of the patient's ability to keep the car on the road. Three accuracy scores were obtained: at the fixed low speed, at the fixed high speed, and at the variable patient-controlled speed. A "speed" score, the time required for the trial when the patient was controlling his own speed, was also obtained. During this phase of the test the patient was asked to drive as rapidly and as accurately as he could. A derived score was also 
computed by taking the ratio of the difference between the accuracy score at low fixed speed and the accuracy score at patient-controlled speed, and dividing by the time score. This speed:accuracy ratio, which indicated the degree to which speed was sacrificed for accuracy, or vice versa, may be interpreted as a measure of judgment. The seven scores on the Driver Test thus included three accuracy scores, one speed score, one judgment score, and two reaction-time scores.

B. Vision Tests (7 scores). Tests of the various components of vision that might be affected by psychoactive drugs were conducted on the Bausch and Lomb master model Ortho-Rater, an instrument designed to control illumination, distance, and presentation of stimuli used to test the various functions of vision (Marquis et al., 1957).

Acuity was determined for both far and near vision; depth perception was determined for distant vision only. Vertical and lateral phorias for both near and far vision were also measured. Phoria scores indicate the relative posture or muscular balance of the eyes in relation to each other under conditions of controlled accommodation. A perfect vertical phoria score indicates that the horizontal midline in both the right and left visual fields is in the same axis. A perfect lateral phoria score indicates the same for the vertical midline.

C. Bourdon Alternate Coding Test (4 scores). This test, which depends upon rigidity and attention as well as psychomotor skills (Uhr et al., 1959), consists of rows of dots arranged in units of 3, 4, or 5 dots. The patient is instructed to draw a vertical line through the threedot unit, a horizontal line through the four-dot unit, and no line through the five-dot unit. He is scored for number correct as well as errors for a 45-second test period. He is then told to change his coding method; to draw no line through the three-dot unit, a vertical line through the fourdot unit, and a horizontal line through the five-dot unit, and given a 45second test period. A third 45 -second test period is then run with instructions to follow the first coding procedure for the first line, the second coding procedure for the second line, and to continue to alternate back and forth at the beginning of each new line. Number correct and errors were scored separately, for the first two periods combined, and for the third change-set period.

D. Continuous Attention Test (2 scores). This test consisted of three pages, each containing 100 lines of ten random letter groups, in half of which an " $E$ " was embedded. The patient was instructed to write a plus next to a line which contained an " $E$ " and a zero next to a line that did 
not. A metronome was set to beat at the rate of one per second, and the patient was told to work at this steady rate, doing one line per second. Total correct and number of errors over the standard five-minute test were scored separately.

E. O'Connor Finger Dexterity Test (1 score). In this task, which calls for quick, fine, finger manipulations, the patient is asked to insert $1 / 16$-inch brass pins, in groups of threes, into $1 / 4$-inch holes, working as fast as he can. The number of pins correctly inserted in a 1-minute test period is recorded as the patient's score.

F. Short-Torm Momory and Attention Span (1 score). Digit span forward was tested and scored, according to standard Wechsler-Bellevue procedures (Wechsler, 1944). This test has been shown by Kornetsky et al. (1957) to be sensitive to the effects of phenothiazines and barbiturates, whereas it does not appear to be affected by milder psychoactive drugs, such as meprobamate (Uhr et al., 1959).

G. Tapping Rate ( 1 score). In this test the patient is asked to tap, as rapidly as he can, using a standard telegraph key. He is given two 30-second test periods from which the single combined score of number of taps is obtained.

H. Preferred Tempo (1 score). An electric metronome is turned on and varied in tempo by the experimenter. The patient is then asked to set the metronome to the tempo he prefers.

I. Semantic Differential Test (3 scores). A modified version of Osgood's Semantic Differential (an empirically derived form designed to measure how a person perceives himself, Osgood, 1952) was used to get determinations on three independent aspects of patients' feelings while under the influence of the drug treatments: (1) feelings of activity, (2) feelings of potency, and (3) self-evaluation.

J. Self-Report Check List ( 8 scores). The patient made quick ratings on a seven-point scale as to how he felt on each of cight variables that were related to possible drug effects. (Kelly et al., 1958b). These included three physical feelings: good, tense, and alert; and five psychological feelings: confident, calm, good, tense, and lucky.

\section{RESULTS}

Tables 1 and 2 present the results obtained on the thirty-five variables scored from the objective test battery, in terms of differences between the effects of the different drug treatments. Table 1 presents the variables 
TABLE 1

Mean Differences in Performance on Behayloral Tests among the Three Combinations of Drug Treatments

\begin{tabular}{|c|c|c|c|c|c|c|}
\hline \multirow[b]{3}{*}{ Variable } & \multicolumn{6}{|c|}{ Combination of Drug Treatments } \\
\hline & \multicolumn{2}{|c|}{$\begin{array}{c}\text { Placebo } \\
\text { vg } \\
1 \mathrm{mg} \text { syrosingopine }\end{array}$} & \multicolumn{2}{|c|}{$\begin{array}{c}\text { Placebo } \\
\text { vs } \\
5 \mathrm{mg} \text { syrosingopine }\end{array}$} & \multicolumn{2}{|c|}{$\begin{array}{c}1 \mathrm{mg} \\
\text { vs } \\
5 \mathrm{mg} . \\
\text { syrosingopine }\end{array}$} \\
\hline & $\begin{array}{c}\text { Mean } \\
\text { difference }^{n}\end{array}$ & $\begin{array}{l}\text { Standard } \\
\text { error }^{b}\end{array}$ & $\begin{array}{c}\text { Mean } \\
\text { difference }{ }^{a}\end{array}$ & $\begin{array}{l}\text { Standard } \\
\text { error }\end{array}$ & $\begin{array}{c}\text { Mean } \\
\text { difference }\end{array}$ & $\begin{array}{l}\text { Standard } \\
\text { error }^{b}\end{array}$ \\
\hline \multirow{2}{*}{\multicolumn{7}{|c|}{$\begin{array}{l}\text { A. Driver test } \\
\text { Slow speed: }\end{array}$}} \\
\hline & & & & & & \\
\hline 1. Accuracy & 3.6 & 4.96 & -4.0 & 4.13 & -7.6 & 5.33 \\
\hline $\begin{array}{l}\text { 2. Reaction time } \\
\text { Fast speed: }\end{array}$ & 1.9 & 1.98 & -0.4 & 1.70 & -2.3 & 1.66 \\
\hline 3. Accuracy & 0.7 & 6.08 & 4.8 & 4.61 & 4.1 & 5.56 \\
\hline $\begin{array}{l}\text { 4. Reaction time } \\
\text { Variable: }\end{array}$ & 1.4 & 1.23 & 1.9 & 1.66 & 0.5 & 1.51 \\
\hline 5. Accuracy & 0.0 & 5.42 & 6.4 & 7.16 & 6.4 & 6.09 \\
\hline 6. Total time & 2.0 & 7.0 & -5.0 & 9.1 & -7.0 & 6.1 \\
\hline 7. Judgment & 1.18 & 28.55 & -3.82 & 32.13 & 1.19 & 29.61 \\
\hline \multicolumn{7}{|l|}{$\begin{array}{l}\text { B. Vision tests } \\
\text { Acuity: }\end{array}$} \\
\hline 8. Near & -2 & 2.8 & 0 & 2.7 & 2 & 3.0 \\
\hline $\begin{array}{l}\text { 9. Far } \\
\text { Phoria (vertical): }\end{array}$ & -1 & 2.8 & -3 & 2.2 & -2 & 2.4 \\
\hline 10. Near & 1 & 2.0 & 2 & 1.9 & 1 & 1.7 \\
\hline 11. Far & -2 & 1.5 & -2 & 1.6 & 0 & 1.9 \\
\hline $\begin{array}{l}\text { Phoria (lateral): } \\
\text { 12. Near }\end{array}$ & & & & & & \\
\hline $\begin{array}{l}\text { 12. Near } \\
\text { 13. Far }\end{array}$ & $\begin{array}{l}-3 \\
-6\end{array}$ & $\begin{array}{l}3.3 \\
2.4 *\end{array}$ & $\begin{array}{l}4 \\
1\end{array}$ & $\begin{array}{l}3.4 \\
2.9\end{array}$ & $\begin{array}{l}7 \\
7\end{array}$ & $\begin{array}{l}3.6 \\
2.3 * *\end{array}$ \\
\hline 14. Depth & 3 & 2.9 & 2 & 3.6 & -1 & 3.0 \\
\hline \multicolumn{7}{|l|}{ C. Bourdon } \\
\hline 15. Correct & 1.7 & 3.65 & 3.3 & 3.64 & 1.6 & 3.83 \\
\hline $\begin{array}{l}\text { 16. Errors } \\
\text { Shifting: }\end{array}$ & 0.9 & 1.56 & -0.4 & 1.31 & -1.3 & 1.34 \\
\hline 17. Correct & -1.3 & 1.66 & -2.0 & 2.00 & -0.7 & 2.42 \\
\hline 18. Errors & -0.3 & 0.88 & -0.4 & 0.79 & -0.1 & 0.93 \\
\hline \multicolumn{7}{|l|}{ D. Continuous attention } \\
\hline 19. Correct & 1.7 & 1.90 & -0.5 & 2.29 & -2.2 & 2.13 \\
\hline 20. Marked wrong & 2 & 12.5 & 15 & 10.2 & 13 & 8.6 \\
\hline \multicolumn{7}{|l|}{ E. Finger dexterity } \\
\hline 21. Number completed & 5 & 10.6 & -12 & 8.6 & -17 & 10.7 \\
\hline
\end{tabular}


TABLE 1 (Continued)

Mean Differences in Performance on Behavioral Tests among the Three Combinations of Drug Treatments

\begin{tabular}{|c|c|c|c|c|c|c|c|}
\hline & \multicolumn{7}{|c|}{ Combination of Drug Treatments } \\
\hline & \multicolumn{3}{|c|}{$\begin{array}{c}\text { Placebo } \\
\text { vs }\end{array}$} & \multicolumn{2}{|c|}{$\begin{array}{c}\text { Placebou } \\
\text { ys }\end{array}$} & \multicolumn{2}{|c|}{$\begin{array}{l}1 \mathrm{mg}^{\mu} \\
\mathrm{vs}\end{array}$} \\
\hline & $1 \mathrm{mg}$ & syro & ingopine & $5 \mathrm{mg} \mathrm{syr}$ & ngopine & $5 \mathrm{mg}$ syro & ngopine \\
\hline Variable & $\begin{array}{r}\mathrm{Me} \\
\text { differe }\end{array}$ & nce $e^{a}$ & $\begin{array}{l}\text { Standard } \\
\text { error }\end{array}$ & $\begin{array}{c}\text { Mean } \\
\mathrm{d}: \text { ff }_{\text {erence }}{ }^{a}\end{array}$ & $\begin{array}{l}\text { Standard } \\
\text { error }\end{array}$ & $\begin{array}{c}\text { Mean } \\
\text { difference }\end{array}$ & $\begin{array}{c}\text { Standard } \\
\text { error }^{b}\end{array}$ \\
\hline
\end{tabular}

F. Digit span

22. Remembered number

G. Tapping rate

23. Number completed

1.7

5.24

3.2

4.88

1.5

5.10

H. Preferred tempo

24. Beats/minute

3.9

4.71

0.1

$\begin{array}{ll}5.34 & -3.8\end{array}$

3.24

${ }^{a}$ No sign indicates first-listed treatment gave better performance. Minus sign indicates second-listed treatment gave better performance.

h Single asterisk; difference significant beyond the 0.05 level of confidence. Double asterisk: difference significant beyond the 0.01 level of confidence.

that measured overt behavior; Table 2 presents the variables that were scored from self-reports.

The three treatments (placebo, $1 \mathrm{mg}$ syrosingopine, and $5 \mathrm{mg}$ syrosingopine) allowed for three different comparisons between treatments: (1) placebo vs $1 \mathrm{mg}$ syrosingopine, (2) placebo vs $5 \mathrm{mg}$ syrosingopine, and (3) $1 \mathrm{mg}$ vs $5 \mathrm{mg}$ syrosingopine. Means, sigmas (i.e., standard deviations), and correlations were computed for all three treatments. Then the mean differences and the standard error of these differences (which gives a measure of their random fluctuations and thus allows for a test of statistical significance), were computed for all three combinations of tablet treatments for each of the thirty-five variables scored. The critical ratio of the difference was then computed for the evaluation of the significance of each difference.

For the sake of clarity in presentation, only the mean difference and the standard error of this difference are presented in the tables. Those differences whose critical ratios achieved significance are identified by a single asterisk for significance beyond the $5 \%$ level and a double asterisk for significance beyond the $1 \%$ level of probability. (Means, sigmas, correlations, and critical ratios for all the variables can be obtained from 
the authors.) The sign of the mean difference indicates which of the two treatments being compared led to the more favorable performance.

TABLE 2

Mean Differences in Self-Reports among the Three Combinations of Drug Treatments

\begin{tabular}{|c|c|c|c|c|c|c|c|}
\hline \multirow{3}{*}{\multicolumn{2}{|c|}{ Variable }} & \multicolumn{6}{|c|}{ Combination of drug treatments } \\
\hline & & \multicolumn{2}{|c|}{$\begin{array}{c}\text { Placebo } \\
\text { vs } \\
1 \mathrm{mg} \mathrm{syrosingopine}\end{array}$} & \multicolumn{2}{|c|}{$\begin{array}{c}\text { Placebo } \\
\text { vs } \\
5 \text { mgsyrosingopine }\end{array}$} & \multicolumn{2}{|c|}{$\begin{array}{c}1 \mathrm{mg} \\
\mathrm{vs} \\
5 \mathrm{mg} \\
\text { syrasingopine }\end{array}$} \\
\hline & & $\begin{array}{c}\text { Mean } \\
\text { difference }\end{array}$ & $\begin{array}{c}\text { Standard } \\
\text { error }\end{array}$ & $\begin{array}{c}\text { Mean } \\
\text { differens:e }\end{array}$ & $\begin{array}{l}\text { Standard } \\
\text { error }^{b}\end{array}$ & $\begin{array}{c}\text { Mean } \\
\text { difference }{ }^{a}\end{array}$ & $\begin{array}{l}\text { Standard } \\
\text { error }\end{array}$ \\
\hline \multirow[t]{3}{*}{ I. } & Semantic differential & & & & & & \\
\hline & 1. Activity & 5 & 7.4 & 2 & 6.1 & -3 & 5.3 \\
\hline & $\begin{array}{l}\text { 2. Potency } \\
\text { 3. Self-evaluation }\end{array}$ & 3 & 5.4 & 8 & 5.3 & 5 & 5.4 \\
\hline \multirow[t]{11}{*}{$J}$. & Check list & & & & & & \\
\hline & How feel physically: & & & & & & \\
\hline & 4. Good & 1 & 2.2 & 0 & 1.3 & -1 & 2.4 \\
\hline & 5. Tense & -4 & 3.6 & 1 & 3.1 & 5 & 3.8 \\
\hline & 6. Alert. & 3 & 3.2 & 1 & 2.8 & -2 & 2.8 \\
\hline & $\begin{array}{l}\text { How feel psycho- } \\
\text { logically: }\end{array}$ & & & & & & \\
\hline & 7. Confident & -1 & 2.9 & -1 & 2.7 & 0 & 3.4 \\
\hline & 8. Calm & -5 & 3.3 & 0 & 4.3 & 5 & 4.4 \\
\hline & 9. Good & -5 & 2.9 & -5 & $2.4^{*}$ & 0 & 3.2 \\
\hline & 10. Tense & -3 & 4.2 & 1 & 4.0 & 4 & 4.5 \\
\hline & 11. Lucky & 1 & 3.3 & 1 & 2.5 & 0 & 3.1 \\
\hline
\end{tabular}

a No sign indicates first-listed treatment gave better performance. Minus sign indicates second-listed treatment gave better performance.

${ }^{b}$ Asterisk: difference significant beyond the 0.05 level of confidence.

When a relatively large number of variables are tested simultaneously for the effects of different drug treatments, and several combinations of treatments are examined, chance effects alone will lead to a certain number of statistically significant results. The conventional $5 \%$ and $1 \%$ probability levels, which are used in the present study, are set so that chance alone would lead to the achieving of these levels $5 \%$ and $1 \%$ of the time, respectively. With three combinations of thirty-five variables, we would thus expect, by chance alone, at least five significances at the $5 \%$ level, one of which would also be significant at the $1 \%$ level. It thus seems quite likely that the three contrasts found to be significant at the 
$5 \%$ level, one of which was significant at the $1 \%$ level, were all chance occurrences. Syrosingopine, chronically administered in both $1-\mathrm{mg}$ and 5-mg daily doses, does not have any adverse behavioral effects as tested on the present battery of driving, vision, attention, and self-report tasks.

\section{DISCUSSION}

The battery of tests used in this study was chosen to elicit and measure a wide variety of behavior, covering the different functions of a normal human being who must continue his day-to-day activities while under prolonged drug treatment. The simple and complex psychomotor tests used here involve several motor performance factors, such as reaction time, vertical and horizontal tracking, fine muscle dexterity and steadiness, both singly and combined into complex patterns on the driver trainer. These tests, along with the check on the basic components of visual perception, would seem to assess the major behaviors that must continue at a normal level under outpatient treatment.

Several studies give indications of the magnitude of effects to be expected from these tests from a variety of different drugs. Marquis et al. (1957) found small improvements in performance under the effects of $d$-amphetamine sulfate, small decrements under the effects of a single shot of alcohol, and no effects from meprobamate as compared with placebo-all treatments given once to normal subjects. Kelly et al. (1958a, b), examining the chronic effects of meprobamate and prochlorperazine on the performance of normal subjects on an especially large battery of behavioral tests, found a number of individual statistically significant effects, possibly indicating the sensitivity of the tests to these drugs, but concluded that, because of the large number of tests of significance that were conducted, the results of the study as a whole did not appear to indicate more than chance effects. Uhr et al. (in press), testing the chronic effects of meprobamate and of a bromide on the behavior of anxious subjects, found several significant effects from each of these treatments as compared with placebo.

Kristofferson and Cormack (in press), using a driving test and experimental procedure closely modeled after the above-mentioned studies, found several effects from small doses of alcohol but none from Quiactin. Loomis and West (1958b) and Melander (1957) each used laboratory simulated driving tests, each somewhat different in detail. Melander found significant effects from amobarbital and no effects from meprobamate, in contrast to Loomis and West's findings of decrements in per- 
formance from meprobamate as well as from chlorpromazine and secobarbital, but none from phenaglycodol. In a related study, Loomis and West (1958a) found their driving test sensitive to small and to differential doses of alcohol. Kornetsky et al. (1957, 1959), using simple tests of psychomotor performance, found a number of significant effects of several dose levels of chlorpromazine and secobarbital.

The tests of attention and simple intellectual functioning (Bourdon, digit span) have given similar indications, in previous experiments, of some sensitivity to mild drugs whose effects should be on the order of the treatment tested in this study. The studies by Kelly et al. (1958a, b), Uhr et al. (in press), and Kornetsky et al. (1957, 1959), plus unpublished pretest studies conducted with a view to choosing batteries of tests that might be sensitive to drug effects, give indications of occasional slight decrements in performance, probably indicative of some slowing and relaxing of attention and alertness.

Finally, self-report measures of anxiety and feelings have given indications of slight drug effects in decreasing anxiety and activity level, and in increasing such feelings as confidence, calmness, and alertness, but often depend upon the type of subject used. Thus Uhr et al. found the most clear-cut effect of drugs on their population of anxiety neurotics, as opposed to much smaller and somewhat conflicting effects found by Kelly et al. (1958a, b) on their population of normal studies. Heller et al. (1957) found self-reported effects from meprobamate upon one type of patient (anxious) but not upon another (hysteric).

These studies should help the reader in establishing a rough metric of drug effects that might be expected upon the present battery of tests. In general, each test, at some time or another, has been found sensitive to a relatively mild psychoactive drug, and has therefore been chosen as among the best available for a check-out of behavioral effects in an assessment of a new drug. The state of this new science still does not present the experimenter with a ready choice of tests for which well-confirmed statements as to the effects of varying amounts of drugs of varying potencies can be made. Probably a weaker statement can be made with somewhat greater confidence: that effects great enough to be of danger to normal functioning would be detected by these tests.

\section{SUMMARY}

Thirty-two male patients were tested for the chronic effects of treatment under two dose levels of syrosingopine upon objectively measured behavior and subjective reactions. All patients completed three 28-day treatment periods: (a) $1 \mathrm{mg}$ syro- 
singopine, (b) $5 \mathrm{mg}$ syrosingopine, and (c) matching placebo, given daily, and thus served as their own controls. Double-blind administration was effected, and ordering of treatments was counter-balanced across patients, to cancel out any practice effects. At the end of each treatment period, each patient was tested on the battery of behavioral tests.

Thirty-five variables were scored from the test battery and examined statistically for the significance of the differences between all combinations of treatments: (1) placebo vs $1 \mathrm{mg}$ syrosingopine, (2) placebo vs $5 \mathrm{mg}$ syrosingopine, and (3) $1 \mathrm{mg}$ vs $5 \mathrm{mg}$ syrosingopine. Only three critical ratios were significant beyond the $5 \%$ level, when, because of the large number of tests of significance made, five would be expected by chance alone. It therefore seems clear that test behavior was not significantly affected by the drug, in either $1-\mathrm{mg}$ or $5-\mathrm{mg}$ daily doses, as compared with a placebo. Thus, as tested in this experiment, the chronic administration of syrosingopine, both in low and in high doses, gave no adverse behavioral effects.

\section{ACKNOWLEDGMENTS}

The authors wish to thank Mr. Cameron J. Yerian, for his able assistance in testing subjects, Dr. John C. Pollard for his cooperation in the planning stages of the experiment, and $\mathrm{Mr}$. Arthur Platz. We would particularly like to thank the many people on the staff of the State Prison of Southern Michigan, especially Dr. David B. Sher, Mr. John A. White, and Warden W. H. Bannen, who, through their fine cooperation, made possible careful experimental controls, and to Mr. Robert Glass of the Michigan Department of Corrections. Support for this study was provided by Ciba Pharmaceutical Products, Inc. and United States Public Health Service Grant No. M-1871, Dr. James G. Miller, Principal Investigator.

\section{REFERENCES}

Heller, G. C., Walton, D., and Black, D. A. (1957). Meprobamate in the treatment of tension states. J. Mental Sci., 103, 581-588.

Keliy, E. L., Miller, J. G., Marquis, D. G., Gerard, R. W., and Uhr, I. (1958a). Personality differences and continued meprobamate and proclcrperazine administration. A.M.A. Arch. Neurol. Psychiat. 80, 241-246.

Kelly, E. L., Mnller, J. G., Marquis, D. G., Gerard, R. W., and Uhr, L. (1958b). Continued meprobamate and proclorperazine administration and behavior. A.M.A. Arch. Neurol. Psychiat. 80, 247-252.

Kornetsky, C., Humphries, O., and Evarts, E. V. (1957). Comparison of psychological effects of certain centrally arting drugs in man. A.M.A. Arch. Neurol. Psychiat. 77, 318-324.

Kornetsky, C., Pettit, M., Wynne, R., and Evarts, E. V. (1959). A comparison of the psychological effects of acute and chronic administration of chlorpromazine and secobarbital (quinalbarbitone) in schizophrenic patients. J. Mental Sci. 105, 190-199.

Kristofferson, A. B., and Cormack, R. H. A behavioral evaluation of Quiactin. In Drugs and Behavior (L. Uhr and J. G. Miller, eds.). Wiley, New York. In press.

Loomis, T. A., and West, T. C. (1958a). The influence of alcohol on automobile driving ability, Quart. J. Studies Alc. 19, 30-46. 
Loomis, T. A., and West, T. C. (1958b). Comparative sedative effects of a barbiturate and some tranquilizer drugs on normal subjects. J. Pharmacol. Expll. Therap. 122, 525-531.

Marquis, D. G., Kelly, E. L., Miller, J. G., Gerard, R. W., and Rapoport, A. (1957). Experimental studies of behavioral effects of meprobamate on normal subjects. Ann. N. Y. Acad. Sci. 67, 701-711.

MELANDer, B. (1957). Psychotechnological investigation of car drivers in model equipment. Translated by the Mental Health Research Institute, Ann Arbor, Michigan, from the draft from the Research Division of $A / B$ Kabi, Stockholm.

Osgoon, C. E. (1952). The nature and measurement of meaning. Psychol. Bull. 49, 197-237.

Uhr, L., Pollard, J. C., and Miller, J. G. (1959). Behavioral effects of chronic administration of psychoactive drugs to anxious patients. Psychopharmacologia. In press.

WeCHSLER, D. (1944). The measurement of adult intelligence, 3rd ed. Williams and Wilkins, Baltimore, Maryland. 